\title{
Enhancing Contrast of Image by Filtering and Brightness Preserving Algorithm
}

\author{
Ribana K $\mathbf{1}^{1}$ \\ Assistant professor, Department of ECE, M. Kumarasamy College of Engineering, Karur, India ${ }^{1}$
}

\begin{abstract}
Visualisation of an image is an important parameter in the area of image processing. To obtain the better visualisation contrast enhancement is one of the important techniques. Contrast of an image is easily upgraded by maximize the difference between the adjacent pixel values, that can be obtained by the traditional technique histogram equalisation but in that some disadvantages like noise amplification, over and under enhancement may be present in that technique because of the uniform histogram in an output image. In order to minimise the presence of noise in an output image our proposed technique uses filtering operation before the enhancement process so the final image will have better visual quality with minimum brightness error value.
\end{abstract}

Keywords: Contrast Enhancement, Uniform Histogram Equalisation, Filtering Operation, Noise.

\section{INTRODUCTION}

Contrast enhancement can obtain by either direct or indirect enhancement technique. Direct enhancement is the process of modifying the histogram of an original image [1] on the other hand indirect enhancement is obtained by the modification in an image through transformation [2] of an original image from one domain to the another domain that is from spatial to frequency domain by the transformation techniques like Fourier or wavelet transformation techniques.

In the case of direct enhancement method histogram modification plays an important role [3]. Histogram modification can be performed by remapping the original image pixel values in to some other pixel values by performing some operations. [4]

In an indirect enhancement method the original image can be divided in to various frequency bands then that frequency bands can be processed using some algorithm which makes the better enhancement [5].

\section{PREVIOUS WORK}

This part describes previous algorithms and methods for contrast enhancement in the literature

\section{A. Histogram Equalisation (HE)}

Histogram equalization is the direct enhancement technique. That can be obtained by calculating the histogram of an original image [6], and the cumulative function of the histogram calculation it is use full for remapping of original pixel values in to the some other pixel value to obtain the uniform histogram at the output image, but output image is having the noise amplification and higher brightness error values because of over and under enhancement of this algorithm [7].
B. Brightness Preserving Bi-Histogram Equalization (BBHE)

BBHE sub divide the original image histogram in to two different histograms with the reference of the mean value of an original image. Then the sub divided image histograms are equalized separately by histogram equalization [8]. The following steps to be performed to obtain Brightness preserving Bi-Histogram Equalization (BBHE).

Step 1: Mean Computation: Mean value of the input image $\left(x_{m}\right)$ is computed

STEP 2: Bi-Histogram Formation: From the mean value the input image histogram is decayed in to two sub image histogram $x_{a}$ and $x_{b}$ is represented by,

$x_{a}=\left\{x(i, j) \mid x(i, j) \leq x_{m}\right\}$

$x_{b}=\left\{x(i, j) \mid x(i, j)>x_{m}\right\}$

Where $\mathrm{x}$ is input image $\mathrm{x}=\mathrm{x}_{\mathrm{a}} \cup \mathrm{x}_{\mathrm{b}}, \mathrm{x}_{\mathrm{a}}$ and $\mathrm{x}_{\mathrm{b}}$ are the sub image histogram.

STEP 3: Histogram Equalisation of Sub Images: Histogram equalisation of sub images is performed as same as the Traditional histogram equalisation [10].

C. Dualistic Sub-Image Histogram Equalization

The same steps are followed to obtain the DSIHE instead of mean value the median value is used to subdivide the input image histogram [9].

D. Gamma Correction (GC)

A gamma correction technique changes the pixel values of an image by varying the exponential value (i.e) gamma [10]. The gamma correction is obtained by,

$$
\mathrm{T}(\mathrm{k})=\mathrm{k}_{\max } \times\left(\frac{\mathrm{k}}{\mathrm{k}_{\max }}\right)^{\gamma}
$$


The contrast of an image is improving in a better way but the enhancement is not depends on the input pixel values it enhances the image in a similar way[19].

\section{PROPOSED ALGORITHM}

The proposed algorithm is using the pre-processing technique by adding the filter also. The algorithm is as follows,

Step 1: Image Acquisition

Step 2: filtering

The original image is undergoes the filtering operation for removal of noise presence in an input image due the natural defects like lack of light, noise in image capturing device. In our method median filter is used because of maintain the originality of an input image after enhancement also it performs the filtering operation by using the adjacent image pixel values

Step 3: BBHE of filtered image

The filtered image is enhanced by BBHE technique

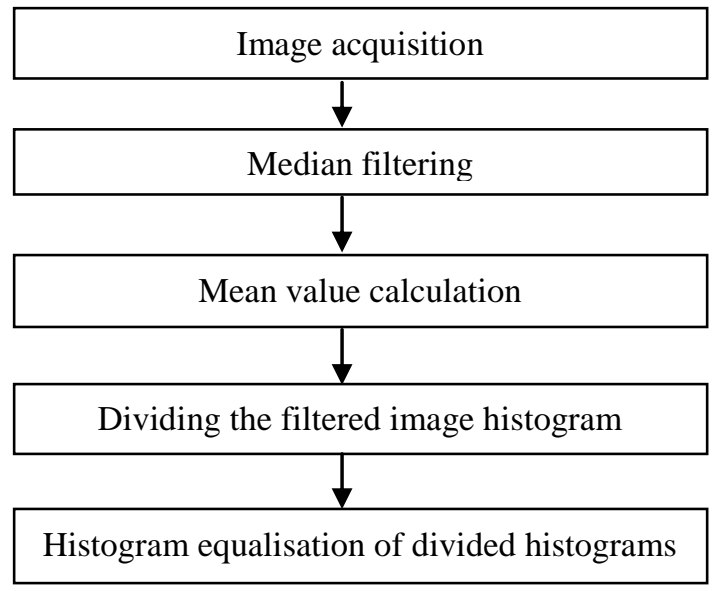

Fig. 1. Proposed algorithm steps

\section{IV.RESULT AND DISCUSSION}

The proposed algorithm is analysed and implemented using MATLAB2013a.The proposed algorithm is compared with Histogram Equalisation (HE), Gamma Correction (GC), Brightness Preserving Bi-Histogram Equalisation (BBHE), Dualistic Sub-Image Histogram Equalisation (DSIHE).when compared with brightness preserving algorithm proposed algorithm is having minimum MSE value and the output image having improved visual quality than the BBHE algorithm.

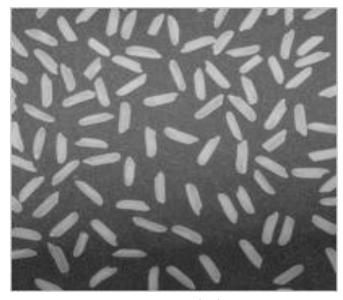

(a)

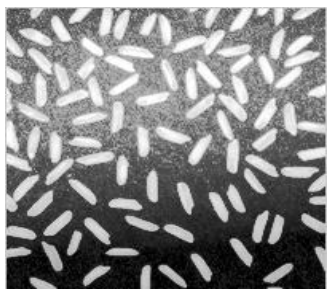

(b)

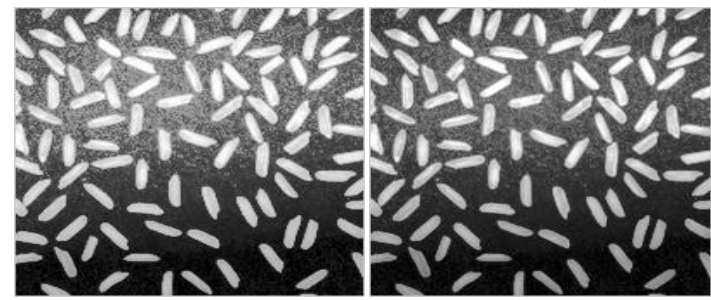

(c)

(d)

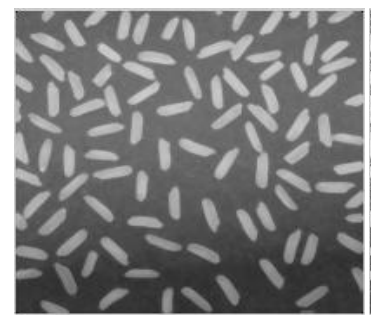

(e)

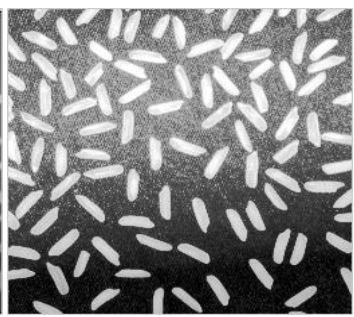

(f)
Fig. 2 .Simulation results of HE, GC, BBHE, DSIHE, AGC and LL band AGC algorithms (a)Original image (b) Histogram Equalised image (c)Brightness Preserving BiHistogram Equalised image (d)Dualistic Sub-Image Histogram Equalisation (e) Gamma Corrected image (f) Proposed image.

TABLE 1 Peak Signal to Noise Ratio (PSNR) For HE, BBHE, DSIHE, GC and proposed algorithms

\begin{tabular}{|l|c|}
\hline ENHANCEMENT METHODS & PSNR (dB) \\
\hline Histogram Equalisation & 16.19 \\
\hline $\begin{array}{l}\text { Brightness Preserving Bi- } \\
\text { Histogram Equalisation }\end{array}$ & 17.28 \\
\hline $\begin{array}{l}\text { Dualistic Sub-Image Histogram } \\
\text { Equalisation }\end{array}$ & 18.24 \\
\hline Gamma Correction & 16.17 \\
\hline Propded algorithm & 38.92 \\
\hline
\end{tabular}

TABLE 2 Mean Square Error (MSE) For HE, BBHE, DSIHE, GC and Proposed agorithm

\begin{tabular}{|l|l|}
\hline \multicolumn{1}{|c|}{ ENHANCEMENT METHODS } & MSE \\
\hline HistogramEqualisation & 16.17 \\
\hline $\begin{array}{l}\text { Brightness Preserving Bi-Histogram } \\
\text { Equalisation }\end{array}$ & 9.98 \\
\hline Dualistic Sub-Image Histogram Equalisation & 5.74 \\
\hline Gamma Correction & 7.08 \\
\hline Proposed algorithm & 4.78 \\
\hline
\end{tabular}

\section{CONCLUSION}

In this project, the enhancement of an image is obtained by Brightness Preserving Bi-Histogram Equalization method followed by filtering of original image. The proposed method produces better visual quality as well as good performance in terms of MSE and PSNR values. The proposed method can be extended by varying the filter 


\section{International Journal of Innovative Research in Electrical, Electronics, Instrumentation and Control Engineering ISO 3297:2007 Certified}

Vol. 5, Issue 2, February 2017

types for removal of noise also it can be applied for color images also.

\section{REFERENCES}

[1] S D.Chen A.Ramli 'Minimum Mean Brightness Error Bi-Histogram Equalization In Contrast Enhancement', IEEE Transactions on Consumer Electronics, Vol. 49, No. 4, pp.1310-1319, 2003.

[2] S D. Chen and A R.Ramli 'Contrast Enhancement using Recursive Mean-Separate Histogram Equalization for Scalable Brightness Preservation', IEEE Transactions on Consumer Electronics, Vol. 49, No. 4, pp. 1301-1309, 2003.

[3] Y. Kim 'Contrast enhancement using brightness preserving bihistogram equalization', IEEE Transactions. Consumer Electronics, Vol. 43, No. 1, pp. 1-8, 1997.

[4] V Kavitha, V Palanisamy, 'New Burst Assembly and Scheduling T technique for Optical Burst Switching Networks', Journal of Computer Science, Vol. 9, Issue 8, pp.1030-1040, 2013.

[5] C H Ooi. and N A. Mat Isa 'Adaptive Contrast Enhancement Methods with Brightness Preserving', IEEE Transactions on Consumer Electronics, Vol. 56, No. 4 pp. 2543-2551. 2010.

[6] S Palanivel Rajan, "Review and Investigations on Future Research Directions of Mobile Based Tele care System for Cardiac Surveillance", Journal of Applied Research and Technology, Vol.13, Issue 4, pp.454-460, 2015.

[7] S Palanivel Rajan, M Paranthaman C,Vivek, "Design and Enhancement of Wideband Reconfigurability using Two E-Shaped Patch Antenna", Asian Journal of Research in Social Sciences and Humanities, ISSN : 2249-7315, Vol.6, Issue 9, pp. 317-327, 2016.

[8] S Palanivel Rajan, "A Significant and Vital Glance on "Stress and Fitness Monitoring Embedded on a Modern Telematics Platform", Telemedicine and e-Health Journal, Vol.20, Issue 8, pp.757-758, 2014.

[9] S Palanivel Rajan, T Dinesh, "Systematic Review on Wearable Driver Vigilance System with Future Research Directions", International Journal of Applied Engineering Research, Vol. 2, Issue 2, pp.627-632, 2015.

[10] S Palanivel Rajan, S Vijayprasath, "Performance Investigation of an Implicit Instrumentation Tool for Deadened Patients Using Common Eye Developments as a Paradigm", International Journal of Applied Engineering Research, Vol.10, Issue 1, pp.925-929, 2015.

[11] N Sengee. A Sengee. and H K. Choi 'Image Contrast Enhancement using Bi-Histogram Equalization with Neighborhood Metrics', IEEE Transactions on Consumer Electronics, Vol. 56, No. 4, pp. 2727-2734,2010.

[12] K S Sim. C P Tso. and Y. Tan 'Recursive sub-image histogram equalization applied to gray-scale images', Pattern Recognition. Letter, Vol. 28, pp. 1209-1221, 2007.

[13] Tarik Arici, Salih Dikbas 'A Histogram Modification Framework and Its Application for Image Contrast Enhancement',IEEE Transactions on Image Processing ,Vol. 18, No. 9, pp. 1921-1935, 2009.

[14] C Vivek, S Palanivel Rajan, "Z-TCAM : An Efficient Memory Architecture Based TCAM", Asian Journal of Information Technology, Vol.15, Issue 3, pp.448-454, 2016.

[15] C Vivek, S Palanivel Rajan, "Design of Data Aware Low Power Area Efficient Datapaths for Processing Elements in a Reconfigurable System", International Journal of Computer Science and Information Security, ISSN : 1947-5500, Vol.14, Issue 9, pp. 1100-1113, 2016.

[16] S.Palanivel Rajan, T.Dinesh, "Analysis of Human Brain Disorders for Effectual Hippocampus Surveillance", International Journal of Modern Sciences and Engineering Technology, ISSN 2349-3755, Vol. No.: 2, Issue No.: 2, pages: 38-45, 2015.

[17] S.Palanivel Rajan, K.Sheik Davood, "Performance Evaluation on Automatic Follicles Detection in the Ovary", International Journal of Applied Engineering Research, ISSN No.: 0973- 4562, Vol. 10, Issue 55, pp. 1-5, 2015.

[18] S.Palanivel Rajan, R.Sukanesh, "Experimental Studies on Intelligent, Wearable and Automated Wireless Mobile Tele-Alert
System for Continuous Cardiac Surveillance", Journal of Applied Research and Technology, ISSN No.: 1665-6423, Vol. No. 11, Issue No.: 1, pp.133-143, 2013.

[19] S.Palanivel Rajan, R.Sukanesh, S.Vijayprasath, "Analysis and Effective Implementation of Mobile Based Tele-Alert System for Enhancing Remote Health-Care Scenario", HealthMED Journal, ISSN No. : 1840-2291, Vol. No. 6, Issue 7, pp. 2370-2377, 2012.

[20] S.Palanivel Rajan, R.Sukanesh, S.Vijayprasath, "Design and Development of Mobile Based Smart Tele-Health Care System for Remote Patients", European Journal of Scientific Research, ISSN No.: 1450-216X/1450-202X, Vol. No. 70, Issue 1, pp. 148-158, 2012.

[21] S.Palanivel Rajan, Sukanesh, R, et.al., "Performance Analysis Of Mobile Phone Radiation Minimization Through Characteristic Impedance Measurement", International Journal of Computer Science Issues, Vol. 9, Issue 2, p540, 2012.

[22] C Vivek, S Palanivel Rajan, V Kavitha, "Implementation of High Speed Area Efficient Variable Latency Adder", Asian Journal of Research in Social Sciences and Humanities, Vol. 6, Issue : 9, pp.306-316, 2016

[23] S.Palanivel Rajan, R.Sukanesh, "Viable Investigations and Real Time Recitation of Enhanced ECG Based Cardiac Tele-Monitoring System for Home-Care Applications: A Systematic Evaluation”, Telemedicine and e-Health Journal, ISSN: 1530-5627, Online ISSN: 1556-3669, Vol. No.: 19, Issue No.: 4, pp. 278-286, 2013.

[24] S.Palanivel Rajan, et.al., "Intelligent Wireless Mobile Patient Monitoring System", IEEE Digital Library Xplore, ISBN No. 9781-4244-7769-2, INSPEC Accession Number: 11745297, IEEE Catalog Number: CFP1044K-ART, pp. 540-543, 2010.

[25] S.Palanivel Rajan, et.al., "Cellular Phone based Biomedical System for Health Care”, IEEE Digital Library Xplore, ISBN No. 978-14244-7769-2, INSPEC Accession Number: 11745436, IEEE Catalog Number: CFP1044K-ART, pp.550-553, 2010.

[26] S.Palanivel Rajan, et.al., "Performance Evaluation of Mobile Phone Radiation Minimization through Characteristic Impedance Measurement for Health-Care Applications", IEEE Digital Library Xplore, ISBN : 978-1-4673-2047-4, IEEE Catalog Number: CFP1221T-CDR, 2012.

[27] S.Palanivel Rajan, et.al., "Experimental Explorations on EOG Signal Processing for Real Time Applications in LabVIEW", IEEE Digital Library Xplore, ISBN : 978-1-4673-2047-4, IEEE Catalog Number: CFP1221T-CDR, 2012.

[28] S.Palanivel Rajan, et.al., "Visual and tag-based social image search based on hypergraph ranking method", IEEE Digital Library Xplore, ISBN : 978-1-4799-3835-3, INSPEC Accession Number : 14916051, DOI : 10.1109/ICICES.2014.7034079, 2015.

[29] Agnus Swarnanisha Lakshmi, S.Palanivel Rajan, "Scheduled H and X Medicine Dispenser PoC Design", Journal of Chemical and Pharmaceutical Sciences, ISSN No.: 0974-2115, Special Issue : 8 , pp. 1-4, 2016.

[30] S. Palanivel Rajan, C.Vivek, "Blending Augmented Reality and Cloud - Need of the hour and an innovative approach", Journal of Chemical and Pharmaceutical Sciences, ISSN No.: 0974-2115, Special Issue : 8, pp. 23-27, 2016.

[31] S. Palanivel Rajan, M.Poovizhi, "Design of Patch Antenna Array for Radar Communication", Journal of Chemical and Pharmaceutical Sciences, ISSN No.: 0974-2115, Special Issue : 8, pp. 38-40, 2016.

[32] C.Vivek, S. Palanivel Rajan, "Review of Low Power and High Speed Implementation of 3-bit Flash Analog to Digital Converter", Journal of Chemical and Pharmaceutical Sciences, ISSN No.: 09742115, Special Issue : 8, pp. 74-78, 2016.

[33] S.Palanivel Rajan, C.Vivek, M.Paranthaman, "Feasibility Analysis of Portable Electroencephalography Based Abnormal Fatigue Detection and Tele-Surveillance System", International Journal of Computer Science and Information Security, ISSN No.: 1947-5500, Vol. No.: 14, Issue : 8, pp. 711-722, 2016 